\title{
Airway Surface Liquid Contains Endogenous DNase Activity Which CAN BE ACTIVATED By ExOgEnous Magnesium
}

\author{
J. Rosenecker ${ }^{1}$, S. Naundorf ${ }^{1}$, C. Rudolph ${ }^{1,2}$ \\ ${ }^{1}$ Department of Pediatrics, Ludwig-Maximilians University, Munich, Germany \\ ${ }^{2}$ Free University of Berlin, Department of Pharmacy, Berlin, Germany
}

\begin{abstract}
Introduction: The removal of highly viscous mucus from the airways is an important task in the treatment of chronic lung disease like in cystic fibrosis. The inhalation of recombinant human DNase- I (rhDNaseI) is used to facilitate the removal of tenacious airway secretions in different lung diseases and especially in CF. Little is known about endogenous DNase activity in the airway surface liquid. Therefore, we analysed bronchoalveolar lavage fluid (BAL) and exhaled breath condensate $(\mathrm{EBC})$ for the presence of endogenous DNase activity.

Methods: The degradation of plasmid DNA by BAL from patients who had diagnostic bronchoscopy and bronchoalveolar lavage was analyzed. In a group of CF patients and healthy control volunteers the exhaled breath condensate was obtained and also analyzed for the ability to degrade plasmid DNA. In addition, the ability of magnesium to activate endogenous DNase activity in BAL and exhaled breath condensate was investigated.

Results: The analyzed BAL samples degraded plasmid DNA only after preincubation with magnesium. When analyzing the exhaled breath condensate the samples obtained from the healthy volunteers showed no DNase activity even after preincubation with magnesium, whereas in one of the two samples obtained from CF patients we found a DNase activity after preincubation with magnesium.

Conclusion: Increasing the magnesium concentration in the airway surface liquid by aerosolisation of magnesium solutions or oral magnesium supplements could improve the removal of highly viscous mucus in chronic lung disease by activating endogenous DNase activity.
\end{abstract}

\section{INTRODUCTION}

Cystic fibrosis (CF) is the commonest lethal autosomal-recessive disease in Caucasians, affecting approximately 30,000 people in the European Union. Progressive pulmonary disease remains the primary cause of morbidity and mortality, accounting for over $90 \%$ of $\mathrm{CF}$ deaths. Improved care has led to an improvement in the life expectancy: in the 1950s, life expectancy was less than 1 year, but has steadily risen, with predicted survival extending to 33.4 years in 2001 [1].

CF is caused by a genetic defect in a single gene located on the long arm of chromosome 7 that encodes the cystic fibrosis transmembrane conductance regulator (CFTR) gene. Defective CFTR function leads to reduced chloride secretion into the airway lumen and enhanced sodium reabsorption from it, resulting in reduced airway surface liquid volume and underhydrated mucus, which in turn leads to impaired mucociliary clearance $[2,3]$. An increased bacterial survival in the airways can be observed and chronic endobronchial infection, initially with Staphylococcus aureus and Haemophilus influenzae, and later with Pseudomonas aeruginosa takes place. An intense inflammatory response dominated by an influx of neutrophil granulocytes occurs in response to infection. These neutrophil granulocytes die together with the bacteria and to a lesser extent the airway epithelia cells and release their nuclear DNA which leads to sticky and tenacious mucus secretions which obstruct the airway lumen and reduce the already altered mucocililary clearance [4].

The introduction of rhDNase-I aerosolisation in the treatment of CF patients has improved the removal of tenacious airway surface secretions by hydrolyzing the phosphodiester bonds of the DNA chains, resulting in shorter oligonucleotides. Clinical trials have shown that rhDNAse improved lung function in CF patients [5, 6]. Little is known about endogenous DNase activity in the airway surface liquid. Therefore, we analysed bronchoalveolar lavage fluid (BAL) and exhaled breath condensate for the presence of endogenous DNase activity.

\section{Methods}

Bronchoalveolar lavage fluid (BAL) was taken from 4 non-CF patients who gave informed consent and underwent diagnostic bronchoscopy. Patients were recruited through the Department of Internal Medicine, Klinikum rechts der Isar, Technische Universität München. Bronchoscopy was carried out on the nasal route with intravenous sedation with midazolam, and local anesthesia with $1.5 \%$ lidocaine. ECG, pulse oximetry, and oxygen insufflation (2 L/min) were maintained throughout the whole procedure. Bronchoalveolar lavage of the middle lobe or lingual segment was performed after wedging the bronchoscope in the respective lung sub-segment with five 20-ml aliquots of pre-warmed $37^{\circ} \mathrm{C}$ phospahte-buffered saline. Instillation was performed through the working channel of the bronchoscope via a hand-operated syringe. The fluid was recovered with the help of a suc- 
tion trap to which mechanical, low negative pressure (approximately - $40 \mathrm{~mm} \mathrm{Hg}$ ) was applied. The recovery was stored on ice in a siliconised $100 \mathrm{ml}$ container and immediately transported to the laboratory for further processing and analysis. For the removal of cells, the BAL was centrifuged for $15 \mathrm{~min}$ at $270 \mathrm{~g}$ and $4{ }^{\circ} \mathrm{C}$, and the pellet was discarded. After the determination of phospholipid and protein content, the BAL was stored at $-80^{\circ} \mathrm{C}$. The phospholipid concentration was in the range of $9-0.56 \mu \mathrm{g} / \mathrm{ml}$.

Exhaled breath condensate (EBC) was obtained from two healthy adults and two adult cystic fibrosis patients by standard procedure. Two CF patients were recruited trough the Adult Cystic Fibrosis Service at the Department of Internal Medicine at the Johann Wolfgang Goethe- Universität Frankfurt/Main. NonCF control subjects were recruited from staff at the Department of Internal Medicine at the Johann Wolfgang Goethe- Universität Frankfurt/Main. Prior to collection of EBC, subjects rinsed their mouths with water. Subjects then breathed through a Jaeger Ecoscreen EBC collection device (Jaeger, Hoechberg, Germany). Around $500 \mu \mathrm{l}-800 \mu \mathrm{l}$ of EBC were collected from each individual. Samples were stored at $-80^{\circ} \mathrm{C}$.

DNase Activity in the BAL/ EBC

Restriction fragments of $4.5 \mu \mathrm{g}$ plasmid DNA in distilled water( EGFP-N1;Palo Alto, USA; generated by restriction with EcoRI and NotI) were incubated with
$\mathrm{BAL}$ or $\mathrm{EBC}(130 \mu \mathrm{l}) 24 \mathrm{~h}$ at $37^{\circ} \mathrm{C}$ in the presence or absence of $1 \mathrm{mM}$ EDTA, $1 \mathrm{mM}$ EGTA, $10 \mathrm{mM} \mathrm{MgCl}_{2}$. EDTA and EGTA were added to remove endogenous calcium and magnesium and establish equal conditions in all samples. As positive control $0.05 \mathrm{U}$ DNase / $\mu \mathrm{g}$ DNA in activity buffer was added and incubated for $24 \mathrm{~h}$ at $37^{\circ} \mathrm{C}$ (lane P1 and P2 in Figs. 1 and 2). As negative control only restriction fragments were added in the presence (lane N2) or absence of $1 \mathrm{mM}$ EDTA, $1 \mathrm{mM}$ EGTA, $10 \mathrm{mM} \mathrm{MgCl}$ (lane N1). The reaction was terminated by the addition of sodiumdodecylsulfate to a final concentration of $0.5 \mathrm{M}$ for $15 \mathrm{~min}$. DNA was recovered from the aqueus phase of two subsequent phenol/chloroform extractions and a final extraction with chloroform, precipitated with two volumes of ethanol, separated by $1 \%$ agarose/TAE gel electrophoresis and visualized by ethidiumbromide staining.

To compare the effect of magnesium and calcium ions on DNase activity a DNA degradation assay was performed in the presence or absence of $\mathrm{MgCl}_{2}$ or $\mathrm{CaCl}_{2}$. Plasmid DNA (pEGFP-N1) was digested with ECORI and NOTI and then incubated with DNase-I at $37^{\circ} \mathrm{C}$ with increasing concentrations of $\mathrm{MgCl}_{2}$ or $\mathrm{CaCl}_{2}$ overnight.

\section{RESULTS}

The results of the DNase activity of the tested BAL samples is shown in Figure 1. At baseline, no DNase activity could be detected in the samples as evidenced

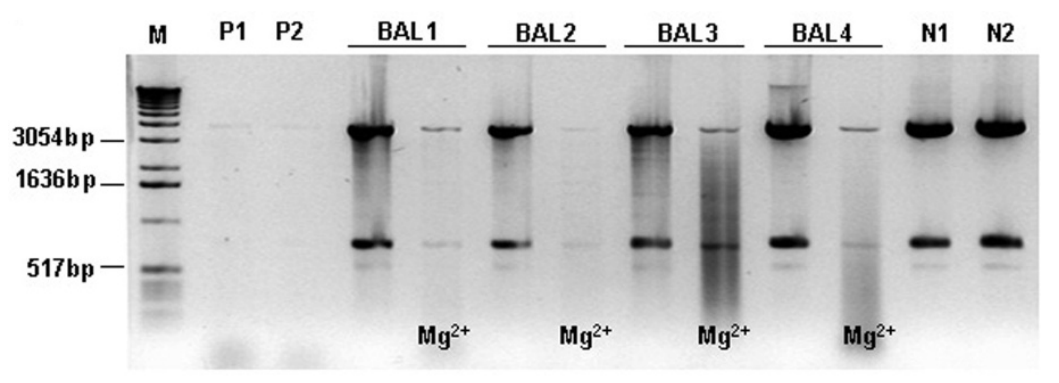

\begin{tabular}{|c|c|c|c|c|c|c|c|c|c|c|c|c|}
\hline & P1 & P2 & 1 & 1 & 2 & 2 & 3 & 3 & 4 & 4 & N1 & N2 \\
\hline DNA & + & + & + & + & + & + & + & + & + & + & + & + \\
\hline EDTA & & + & & + & & + & & + & & + & & + \\
\hline EGTA & & + & & + & & + & & + & & + & & + \\
\hline $\mathrm{MgCl}_{2}$ & & + & & + & & + & & + & & + & & + \\
\hline BAL & & & + & + & + & + & + & + & + & + & & \\
\hline DNase & + & + & & & & & & & & & & \\
\hline
\end{tabular}

Fig. 1. Digestion of restricted plasmid DNA (pEGFP-N1,generated by restriction with EcoRI and NotI) by BAL samples or

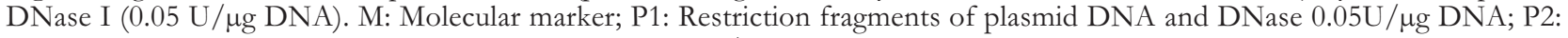
Restriction fragments of plasmid DNA and DNase $0.05 \mathrm{U} / \mu \mathrm{g}$ in $1 \mathrm{mM}$ EDTA, $1 \mathrm{mM} \mathrm{EGTA,} 10 \mathrm{mM} \mathrm{MgCl}{ }_{2}$; BAL 1 first lane: Restriction fragments of plasmid DNA and $130 \mu \mathrm{l} \mathrm{BAL} \mathrm{1;} \mathrm{second} \mathrm{lane:} \mathrm{Restriction} \mathrm{fragments} \mathrm{of} \mathrm{plasmid} \mathrm{DNA} \mathrm{and} 130 \mu \mathrm{l}$ BAL 1 in $1 \mathrm{mM}$ EDTA, $1 \mathrm{mM}$ EGTA, $10 \mathrm{mM} \mathrm{MgCl}_{2}$; BAL 2 first lane: Restriction fragments of plasmid DNA and $130 \mu \mathrm{l} \mathrm{BAL} \mathrm{2;} \mathrm{sec-}$ ond lane: Restriction fragments of plasmid DNA and $130 \mu \mathrm{lBAL} 2$ in $1 \mathrm{mM}$ EDTA, 1mM EGTA, 10mM MgCl ${ }_{2}$, BAL 3 first lane: Restriction fragments of plasmid DNA and $130 \mu \mathrm{l} \mathrm{BAL} \mathrm{3;} \mathrm{second} \mathrm{lane:} \mathrm{Restriction} \mathrm{fragments} \mathrm{of} \mathrm{plasmid} \mathrm{DNA} \mathrm{and} 130 \mu \mathrm{l}$ BAL 3 in $1 \mathrm{mM}$ EDTA, $1 \mathrm{mM}$ EGTA, $10 \mathrm{mM} \mathrm{MgCl}_{2}$; BAL 4 first lane: Restriction fragments of plasmid DNA and $130 \mu \mathrm{l}$ BAL 4 ; second lane: Restriction fragments of plasmid DNA and $130 \mu \mathrm{l}$ BAL 4 in $1 \mathrm{mM}$ EDTA, $1 \mathrm{mM}$ EGTA, $10 \mathrm{mM} \mathrm{MgCl}$. 


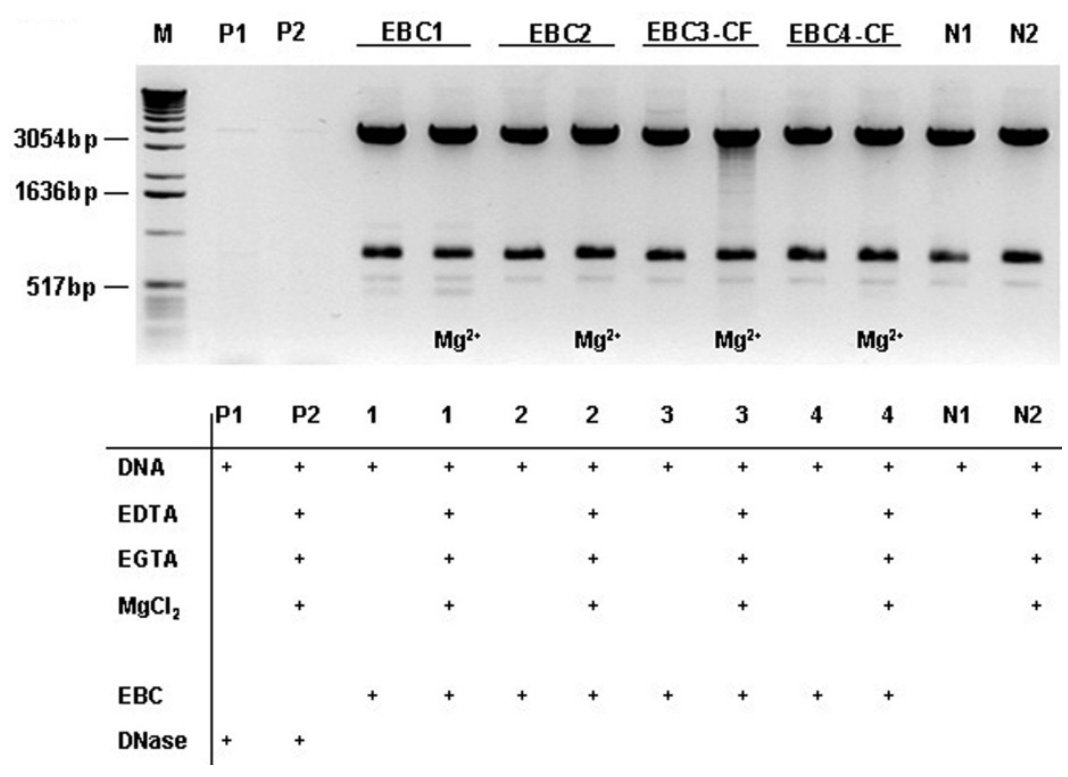

Fig. 2. Digestion of restricted plasmid DNA (pEGFP-N1, generated by restriction with EcoRI and NotI) by exhaled airway condensate or DNase I (0.05 U/ $\mu \mathrm{g}$ DNA). M: Molecular marker; P1: Restriction fragments of plasmid DNA and DNase $0.05 \mathrm{U} / \mu \mathrm{g}$ DNA; P2: Restriction fragments of plasmid DNA and DNase $0.05 \mathrm{U} / \mu \mathrm{g}$ in $1 \mathrm{mM}$ EDTA, $1 \mathrm{mM} \mathrm{EGTA,} 10 \mathrm{mM} \mathrm{MgCl}_{2}$; AK 1 first lane: Restriction fragments of plasmid DNA and $130 \mu \mathrm{l}$ airway condensate 1; second lane: Restriction fragments of plasmid DNA and $130 \mu \mathrm{l}$ airway condensate 1 in $1 \mathrm{mM}$ EDTA, $1 \mathrm{mM}$ EGTA, $10 \mathrm{mM} \mathrm{MgCl} 2$; AK 2 first lane: Restriction fragments of plasmid DNA and $130 \mu \mathrm{l}$ airway condensate 2; second lane: Restriction fragments of plasmid DNA and $130 \mu \mathrm{l}$ airway condensate 2 in $1 \mathrm{mM}$ EDTA, $1 \mathrm{mM}$ EGTA, $10 \mathrm{mM} \mathrm{MgCl}_{2}$; AK3-CF first lane: Restriction fragments of plasmid DNA and 130 $\mu \mathrm{l}$ airway condensate of CF patient L.L.; second lane: Restriction fragments of plasmid DNA and $130 \mu \mathrm{l}$ airway condensate of CF patient L.L. in $1 \mathrm{mM}$ EDTA, $1 \mathrm{mM}$ EGTA, $10 \mathrm{mM} \mathrm{MgCl}_{2}$; AK4-CF first lane: Restriction fragments of plasmid DNA and $130 \mu \mathrm{l}$ of airway condensate of CF patient H.H. ; second lane: Restriction fragments of plasmid DNA and $130 \mu$ of airway condensate of CF patient H.H. in $1 \mathrm{mM}$ EDTA, $1 \mathrm{mM}$ EGTA, $10 \mathrm{mM} \mathrm{MgCl}_{2}$; N1: plasmid DNA (pEGFP-N1) generated by restriction with EcoRI and NotI; N2: plasmid DNA (pEGFP-N1) generated by restriction with EcoRI and NotI in 1mM EDTA, $1 \mathrm{mM}$ EGTA, $10 \mathrm{mM} \mathrm{MgCl}{ }_{2}$.

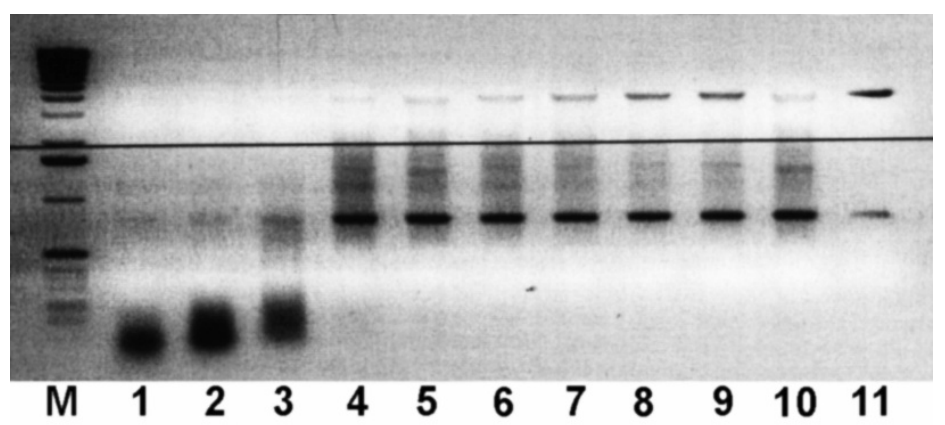

Fig. 3. DNase degradation assay. Plasmid DNA (pEGFP-N1) was digested with ECORI and NOTI and then incubated with DNase-I at $37^{\circ} \mathrm{C}$ with increasing concentrations of $\mathrm{MgCl}_{2}$ or $\mathrm{CaCl}_{2}$ overnight. First lane, Molecular marker; second lane: Restriction fragments of plasmid DNA and $0.05 \mathrm{U} / \mu \mathrm{g}$ DNase in $5 \mathrm{mM} \mathrm{MgCl}_{2}$; third lane, restriction fragments of plasmid DNA and $0.05 \mathrm{U} / \mu \mathrm{g}$ DNase in $1.67 \mathrm{mM} \mathrm{MgCl}$; fourth lane, restriction fragments of plasmid DNA and $0.05 \mathrm{U} / \mu \mathrm{g}$ DNase in 0.56 $\mathrm{mM} \mathrm{MgCl}$; fifth lane restriction fragments of plasmid DNA and $0.05 \mathrm{U} / \mu \mathrm{g}$ DNase in $0.19 \mathrm{mM} \mathrm{MgCl}_{2}$; sixth lane, restriction fragments of plasmid DNA and $0.05 \mathrm{U} / \mu \mathrm{g}$ DNase in $0.06 \mathrm{mM} \mathrm{MgCl}_{2}$; Lane 7, restriction fragments of plasmid DNA and 0.05 $\mathrm{U} / \mu \mathrm{g}$ DNase in $5.0 \mathrm{mM} \mathrm{CaCl}_{2}$; lane 8, restriction fragments of plasmid DNA and $0.05 \mathrm{U} / \mu \mathrm{g}$ DNase in $1.67 \mathrm{mM} \mathrm{CaCl}_{2}$; lane 9 , restriction fragments of plasmid DNA and $0.05 \mathrm{U} / \mu \mathrm{g}$ DNase in $0.56 \mathrm{mM} \mathrm{CaCl}_{2}$; lane 10 , restriction fragments of plasmid DNA and $0.05 \mathrm{U} / \mu \mathrm{g}$ DNase in $0.19 \mathrm{mM} \mathrm{CaCl}_{2}$; lane 11 , restriction fragments of plasmid DNA and $0.05 \mathrm{U} / \mu \mathrm{g} \mathrm{DNase}$ in $0.06 \mathrm{mM}$ $\mathrm{CaCl}_{2}$.

by the intact bands of the restriction fragments of plasmid DNA. In the presence of additional magnesium chloride a strong DNase activity could be detected in the BAL samples 1 and 2, with an almost complete degradation of plasmid DNA. In the BAL samples 3 and 4 a weaker DNase activity was observed (Fig. 1). The analysis of EBC showed no activity in non CF-Patients. In one of the two tested CF patients (AK3-CF) a weak DNase activity could be detected after incubation with magnesium chloride (Fig. 2).

To investigate whether calcium ions could have the same effect on activation of DNase activity we performed a DNA degradation assay in the presence of calcium and magnesium ions (Fig. 3). As a result, calci- 
um had a weaker effect on activation of DNase activity as compared to magnesium.

\section{DISCUSSION}

Airway surface liquid (ASL) is the layer of watery solution that lies between the airway epithelium and the gas phase in the lumen of the airways. Bronchoalveolar lavage and exhaled breath condensate do reflect to some extent the composition of the different substances which prevail in the ASL. Therefore in this study we used BAL and EBC as representative samples of extracellular molecules present in the ASL. Specifically we wanted to analyze whether BAL or EBC do contain endogenous DNase activity. We found that all BAL samples tested contained DNase activity which could only be detected after incubation with magnesium chloride. A reason for this observation is that the amount of ASL present in the BAL is highly diluted due to the procedure of instilling isotonic sodium chloride into the airways prior to obtaining the BAL. Also in one of the CF samples of EBC we could detect a weak DNase activity. The observation that ASL contains endogenous DNase activity could be important for the treatment of CF lung disease. In cystic fibrosis patients respiratory disease is characterized by airway obstruction caused by the accumulation of thick, purulent secretions, which results in recurrent, symptomatic exacerbations. The viscoelasticity of the secretions can be reduced in vitro by recombinant human deoxyribonuclease I (rhDNase), a bioengineered copy of the human enzyme. In patients with cystic fibrosis, the administration of rhDNase reduced exacerbations of respiratory symptoms and resulted in a slight improvement in pulmonary function $[6,7]$. In a recent publication, Sanders et al. could demonstrate that sputum from CF patients who did not benefit from rhDNase-I treatment (so called non-responders) contained significantly lower concentrations of magnesium than sputum from responders. The authors speculate that increasing the magnesium concentration in sputum by, for example, oral magnesium supplements could be a promising new strategy to overcome the failure of rhDNase-I in patients with CF [8]. Based on our data, it could he speculated that cystic fibrosis patients could already benefit from magnesium inhalation due to activation of endogenous DNase activity in the ASL. In the management of cystic fibrosis, isotonic sodium chloride inhalation is widely used as an adjuvant to nebulised salbutamol. Exchanging isotonic sodium chloride against isotonic magnesium could improve the removal of the viscous mucus from the lungs by activating endogenous DNase activity.

Another aspect why cystic fibrosis patients could benefit from inhaled magnesium relates to findings in patients with asthma. Recently Hughes and colleagues [9] reported that the use of isotonic magnesium as an adjuvant to nebulised salbutamol resulted in an enhanced bronchodilator response in the treatment of severe asthma. The authors did not assess the potential mechanisms whereby magnesium enhanced the bronchodilator response to salbutamol. They speculated that possible mechanisms included direct relaxation of bronchial smooth muscle, inhibition of smooth muscle contraction mediated by calcium, increased beta-receptor affinity, inhibition of cholinergic neuromuscular transmission, and prostacyclin generation. Many CF patients routinely inhale nebulised salbutamol with a jet nebulizer to treat airway obstruction and improve mucociliary clearance. In this situation isotonic sodium chloride is used as an adjuvant. Exchanging isotonic sodium solution against isotonic magnesium might improve the bronchodilator response and enhance mucociliary clearance.

The administration of magnesium at the luminal surface might also improve mucociliary clearance in CF patients by inhibiting the CF specific increased absorption of $\mathrm{Na}+$ and fluid across airway epithelia. It has been published that external $\mathrm{Mg} 2+$ produced a dose-dependent inhibition on $\mathrm{ENaC}$ mediated $\mathrm{Na}+$ absorption in cloned mouse $\boldsymbol{\alpha}-\boldsymbol{\beta}-\boldsymbol{\gamma}$-ENaC expressed in Xenopus oocytes [10]. Therefore external magnesium to the airways could lead to a decreased sodium absorption across airway epithelia resulting in an improved airway surface liquid. These effects might be relevant in the course of CF lung disease especially because it was found that hypomagnesaemia in children with cystic fibrosis (CF) is under-recognized [11]. Therefore further studies are justified to evaluate the effect of magnesium inhalation on the course of lung disease in cystic fibrosis.

\section{CONCLUSION}

Our data suggest that ASL contains endogenous DNase activity. It can be speculated from this data, that inhalation of magnesium in patients with cystic fibrosis could have a beneficial effect due to activation of endogenous DNase activity in the airways.

Competing interests: The authors(s) declare that they have no competing interests.

Authors' contributions: Joseph Rosenecker and Carsten Rudolph conceived the study. Joseph Rosenecker wrote the manuscript. Sonja Naundorf carried out all in vitro work and molecular analysis and contributed to the design of the study. All authors read and approved the manuscript.

Acknowledgements: We thank Prof. Dr. Joachim Bargon, Department of Internal Medicine at the Johann Wolfgang GoetheUniversität Frankfurt/Main, and Prof. Dr. Rainer Hauck, Department of Internal Medicine, Klinikum rechts der Isar, Technische Universität München for providing EBC samples respectively BAL samples. We thank Viola Koncz for technical assistance. This work was funded by a grant from the Oberland e.V., a regional Cystic Fibrosis Research Trust.

\section{REFERENCES}

1. Cystic Fibrosis Foundation. Patient registry 2001 Annual report. Bethesda, MD; 2002.

2. Riordan JR: The cystic fibrosis transmembrane conductance regulator. Annu Rev Physiol 1993; 55:609-30

3. Schwiebert EM, Egan ME, Hwang TH, Fulmer SB, Allen SS, Cutting GR, Guggino WB: CFTR regulates outwardly rectifying chloride channels through an autocrine mechanism involving ATP. Cell 1995; 81:1063-73 
4. Konstan MW, Berger M: Infection and inflammation of the lung in cystic fibrosis. In: Cystic fibrosis. Edited by Davis P. New York: Marcel Dekker; 1993; 219-276

5. Fuchs HJ, Borowitz DS, Christiansen DH, Morris EM, Nash ML, Ramsey BW, Rosenstein BJ, Smith AL, Wohl ME: Effect of aerosolized recombinant human DNase on exacerbations of respiratory symptoms and on pulmonary function in patients with cystic fibrosis. The Pulmozyme Study Group. N Engl J Med 1994; 331:637-42

6. Jones AP, Wallis CE: Recombinant human deoxyribonuclease for cystic fibrosis. Cochrane Database Syst Rev 2003, (3):CD001127.

8. Sanders NN, Franckx H, De Boeck K, Haustraete J, De Smedt SC, Demeester J:

Role of magnesium in the failure of rhDNase therapy in patients with cystic fibrosis. Thorax 2006; 61:962-8

9. Hughes R, Goldkorn A, Masoli M, Weatherall M, Burgess C, Beasley R: Use of isotonic nebulised magnesium sulphate as an adjuvant to salbutamol in treatment of severe asthma in adults: randomised placebo-controlled trial. Lancet 2003; 361:2114-7

10. Sheng S, Perry CJ, Kleyman TR: External nickel inhibits epithelial sodium channel by binding to histidine residues within the extracellular domains of alpha and gamma subunits and reducing channel open probability.J Biol Chem 2002; 277: 50098-111
11. Akbar A, Rees JH, Nyamugunduru G, English MW, Spencer DA, Weller PH: Aminoglycoside-associated hypomagnesaemia in children with cystic fibrosis. Acta Paediatr 1999; 88:783-5

Received: April 20, 2009 / Accepted: May 6, 20090

Address for correspondence:

Joseph Rosenecker, M.D.

Department of Pediatrics

University of Munich

Lindwurmstr. $2 \mathrm{a}$

80337 Munich

Germany

Tel.: (49) 8951607711

Fax: (49) 8951607846

Email: Joseph.Rosenecker@med.uni-muenchen.de Sonja.Naundorf@fresenius-biotech.com Carsten.Rudolph@med.uni-muenchen.de 